\title{
LATIHAN DASAR KEPEMIMPINAN UNTUK PEMUDA KELURAHAN BEDAHAN KECAMATAN SAWANGAN KOTA DEPOK
}

\author{
Zainal Arifin Masri, Deden Ibnu Aqil \\ Program Studi Pendidikan Ekonomi \\ Fakultas Ilmu Pendidikan dan Pengetahuan Sosial \\ Universitas Indraprasta PGRI \\ zarifin243@yahoo.com,den.aqil@gmail.com
}

\begin{abstract}
Abstrak
Badan Komunikasi Pemuda Masjid (BKPM) merupakan wadah kegiatan remaja dan pemuda masjid yang ada di kelurahan Bedahan Kecamatan Sawangan. BKPM memiliki tujuan yakni mengembangkan pemuda dan remaja masjid Kelurahan Bedahan Kecamatan Sawangan. Tujuan tersebut dicapai dengan cara : mensinergikan potensi-potensi pemuda dan remaja masjid untuk memperkuat dakwah Islamiyah, melahirkan pemimpin-pemimpin masyarakat dan bangsa yang berbasis kemasjidan. BKPM dalam rangka mewujudkan tujuannya dalam melaksanakan tanggung jawab sosialnya mengadakan pelatihan dan pendidikan untuk remaja dan pemuda masjid pada khususnya dan remaja dan pemuda secara keseluruhan pada umumnya yang ada di Kelurahan Bedahan. Permasalahan yang dihadapi BKPM adalah kurangnya/tidak dimilikinya tenaga ahli dan profesional dari dalam kalangan BKPM. Untuk mengatasi permasalahan tersebut BKPM melakukan kerjasama kemitraan. Institusi kependidikan yang dihubungi oleh BKPM salah satunya adalah Universitas Indraprasta PGRI untuk membantu mengadakan pelatihan dan pendidikan. Untuk kerjasama pada saat ini BKPM dan tim abdimas Unindra PGRI menyelenggarakan : "Latihan Dasar Kepemimpinan Untuk Pemuda Kelurahan Bedahan Kecamatan Sawangan Kota Depok.
\end{abstract}

Keywords : BKPM, Pemuda, Kerjasama kemitraan, Pendidikan dan Pelatihan, Kepemimpinan

\begin{abstract}
The mosque's Youth Communication Agency (BKPM) is a youth and teen activities container mosques that existed in Bedahan village sub district of Sawangan. BKPM has purpose i.e. developing youth and teenager mosque Bedahan village Subdistrict Sawangan.. The objective is achieved by: synergy potential-potential youth and teenager mosque to reinforce the Da'wah Islamiyah, gave birth to the leaders of society and nation-based kemasjidan. BKPM in order to realize its objectives in carrying out its social responsibility conduct training and education for adolescents and youth in particular and the mosque of adolescents and youth as a whole that is in Bedahan village. The problems facing the BKPM is the lack of possession/not experts and professionals from within the ranks of BKPM. To overcome these problems of BKPM cooperation partnership. Educational institutions are contacted by BKPM one was Indraprasta PGRI University to help conduct training and education. For cooperation in the current abdimas team Unindra PGRI and BKPM organizes: "the exercise of leadership for youth Wards Bedahan vilaage subdistrict of Sawangan.
\end{abstract}

Keywords: BKPM, Youth Cooperation, partnerships, training and education, leadership 


\section{PENDAHULUAN}

Kelurahan Bedahan adalah salah satu kelurahan yang ada di Kecamatan Sawangan Kota Depok. Kelurahan Bedahan terletak pada : sebelah Utara berbatasan dengan kelurahan Sawangan Baru, sebelah Selatan berbatasan dengan desa Raga Jaya kecamatan Bojong Gede, sebelah Barat berbatasan dengan kelurahan Pengasinan kecamatan Sawangan, sebelah Timur berbatasan dengan kelurahan Pasir Putih kecamatan Sawangan.

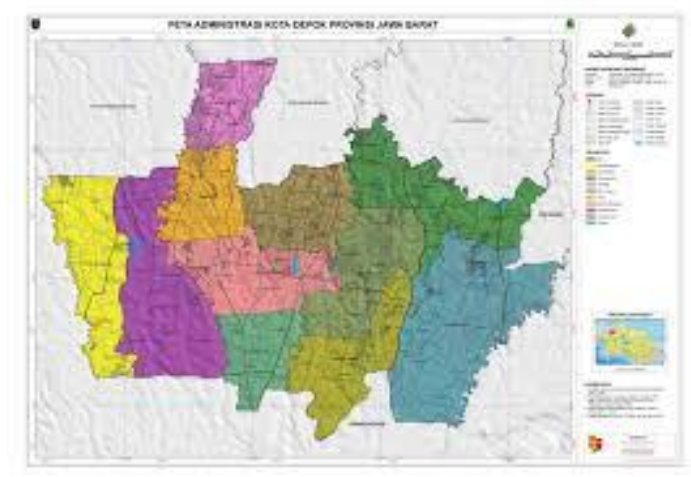

Gambar 1.1 Peta Kota Depok

(Sumber : www.bapeda.depok.go.id diakses 14 April 2017)
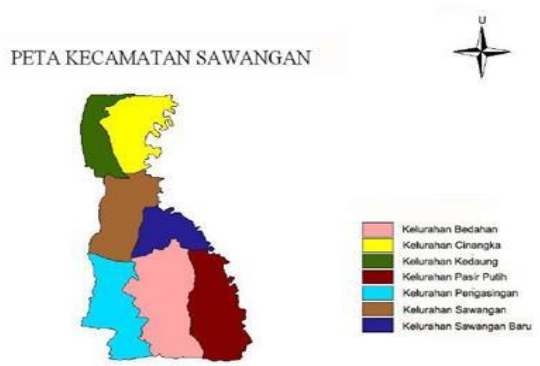

Gambar 1.2 Peta Kec. Sawangan

(Sumber : Www.bapeda.depok.go.id diakses 14 April 2017)

Kelurahan Bedahan memiliki luas wilayah 603 Ha setara dengan $6,03 \mathrm{~km}^{2}$. Jumlah penduduk 64.433 jiwa, dengan kepadatan penduduk $10.685 / \mathrm{km}^{2}$, jumlah Rukun Warga 14 dan Rukun Tetangga 67 dan 6.870 Kepala Keluarga (Sumber : Kantor Kelurahan Bedahan).
Komposisi penduduk berdasarkan usia dapat dilihat pada tabel 1.1.

Tabel 1.1 Komposisi Penduduk Berdasarkan Usia

\begin{tabular}{cr}
\hline Umur & Jumlah \\
\hline$<1$ thn sd 5 thn & 11.702 \\
\hline 5 thn sd 10 thn & 10.905 \\
\hline 11 thn sd 15 thn & 10.826 \\
\hline 16 thn sd 20 thn & 2.320 \\
\hline 21 thn sd 25 thn & 2.134 \\
\hline 26 thn sd 30 thn & 1.453 \\
\hline 31 thn sd 35 thn & 2.220 \\
\hline 36 thn sd 40 thn & 2.015 \\
\hline 41 thn sd 45 thn & 1.614 \\
\hline 46 thn sd 50 thn & 1.616 \\
\hline 51 thn sd 55 thn & 2.163 \\
\hline$>55$ thn & 2.776 \\
\hline
\end{tabular}

Struktur penduduk juga dapat dikelompokkan berdasarkan anak, remaja/pemuda, dewasa dan orang tua. Remaja dan pemuda yakni usia 12 tahun s/d 21 tahun (www.wikipedia.co.id, diakses 13 April 2017). Menururt Hurlock (1964) membagi masa remaja menjadi 2 tahapan, yaitu : remaja awal berusia $12 / 13$ th $-17 / 18$ th, remaja akhir berusia $17 / 18$ th $-21 / 22$ th. Besarnya jumlah remaja dan pemuda di kelurahan Bedahan sebesar 13.146 jiwa, yakni 20,4\% dari jumlah penduduk kelurahan Bedahan. Remaja dan Pemuda ini apabila tidak dibina dengan baik dapat menimbulkan kerawanan lingkungan kelurahan Bedahan. Tindak kriminalitas yang terjadi akhir-akhir ini diberbagai wilayah di Indonesia banyak dilakukan oleh remaja dan pemuda. Disinilah diharapkan peran organisasi-organisasi kepemudaan yang ada di kelurahan Bedahan untuk melakukan pembinaan dan pendidikan mental remaja dan pemuda yang ada.

Salah satu dari organisasi kepemudaan yang ada di kelurahan Bedahan adalah BKPM (Badan Komunikasi Pemuda Masjid). BKPM 
merupakan wadah kegiatan remaja dan pemuda dari 8 (delapan) masjid yang ada di kelurahan Bedahan, yaitu : (1) Masjid Arriyad, (2) Masjid AlMukhlisin, (3) Masjid Al-Hidayah, (4) Masjid Syamsul Iman, (5) Masjid Qurrota A'yun, (6) Masjid Al-Hikmah, (7) Masjid Baiturrahman, (8) Masjid AlHidayah. BKPM didirikan di Bedahan pada tanggal 15 Rabi ul Awal $1419 \mathrm{H}$, bertepatan dengan 7 Juni 1999. Bentuk organisasi adalah Badan Komunikasi kumpulan dari organisasi pemuda dan/atau remaja masjid yang berada di Kelurahan Bedahan. BKPM berasaskan Islam yang dilandasi Al Qur'an dan Sunnah Rasulullah Muhammad SAW. Organisasi ini bersifat Independen dengan menjunjung tinggi Ukhuwah Islamiyah dan Akhlakul Karimah.

Tujuan BKPM adalah mengembangkan dakwah pemuda dan remaja masjid Kelurahan Bedahan. Tujuan tersebut dicapai dengan cara : mensinergikan potensi-potensi pemuda dan remaja masjid untuk memperkuat dakwah Islamiyah, menambah massa pemuda dan remaja masjid yang mampu memakmurkan masjid untuk mendukung kebangkitan Islam, melahirkan pemimpin-pemimpin masyarakat dan bangsa yang berbasis kemasjidan. BKPM menghimpun segenap Pemuda dan Remaja Kelurahan Bedahan yang menjadikan masjid sebagai pusat ibadah, kebudayaan, dan wadah perjuangan ummat serta berfungsi sebagai wahana pembinaan aqidah, akhlaq serta sarana memperkokoh persaudaraan kaum muslimin.

Kegiatan-kegiatan yang dilakukan BKPM antara lain : (1) membina ketaqwaan, keimanan, dan akhlaq Pemuda dan Remaja Masjid Kelurahan Bedahan dengan cara-cara yang sesuai dengan Al Qur`an dan sunah Rasulullah Muhammad SAW yang dilakukan dengan memperhatikan perkembangan zaman, (2) menggali, mengembangkan dan memantapkan segenap potensi pemuda dan remaja masjid baik potensi akal, keilmuan dan budaya yang sifatnya kreatif dan aplikatif yang akan sangat berguna bagi lajunya perkembangan masyarakat, (3) mengembangkan kerjasama, komunikasi, dan persaudaraan antar sesama pemuda dan remaja masjid kelurahan Bedahan dengan warga masyarakat yang lain dari berbagai kalangan, baik perseorangan, lembaga, perhimpunan, pemerintahan, maupun swasta di dalam maupun di luar negeri, (4) mengembangkan dan meningkatkan kepekaan, kepedulian, peran serta, dan solidaritas Pemuda dan Remaja Masjid Kelurahan Bedahan terhadap permasalahan-permasalahan pembinaan generasi muda dalam lingkup ekonomi, pendidikan, sosial dan budaya, (5) usaha-usaha lain yang halal dan benar menurut Al Qur`an dan As Sunnah.

Sarlito (2010) mengatakan bahwa remaja adalah masa yang penuh dengan "badai dan tekanan jiwa", yaitu masa di mana terjadi perubahan besar secara fisik, intelektual dan emosional pada seseorang yang menyebabkan kesedihan dan kebimbangan (konflik) pada yang bersangkutan, serta menimbulkan konflik dengan lingkungannya. Sarlito juga menyatakan bahwa banyak remaja yang mampu beradaptasi dengan baik terhadap perubahan yang terjadi pada dirinya, serta mampu beradaptasi dengan baik terhadap perubahan kebutuhan dan harapan dari orang tua dan masyarakatnya. Kebanyakan remaja mengalami kedua situasi tersebut (penuh konflik atau dapat beradaptasi dengan mulus) secara bergantian (fluktuatif). Hal ini juga berarti tidak sedikit remaja yang melewati masa remajanya yang penuh dengan tekanan dengan mulus. Banyak remaja yang membutuhkan bimbingan dari berbagai pihak termasuk dari 
organisasi kepemudaan yang ada dilingkungannya.

BKPM dalam rangka mewujudkan tujuannya dalam melaksanakan tanggung jawab sosialnya mengadakan pelatihan dan pendidikan untuk remaja dan pemuda. Pelatihan dan pendidikan yang diadakan oleh BKPM dengan mengadakan kerjasama kemitraan dengan institusi lainnya, terutama institusi kependidikan. Institusi kependidi-an yang dihubungi oleh BKPM salah satunya adalah Universitas Indraprasta PGRI untuk membantu mengadakan pelatihan dan pendidikan. Bagi Universitas Indraprasta PGRI, kerjasama kemitraan dengan BKPM merupakan ajang dan wadah pengabdian kepada masyarakat untuk dosen-dosen Universitas Indraprasta PGRI.

Ruang lingkup pelaksanaan kegiatan pengabdian kepada masyarakat, meliputi :

1. Organisasi dan Kepemimpinan

2. Pemuda dan Pembangunan

3. Kewirausahaan Masjid

Melalui kegiatan Pelatihan Dasar Kepemimpinan ini diharapkan dapat membantu mengarahkan para pemuda dilingkungan Bedahan yang makin hari semakin mudah terpengaruhi oleh budaya-budaya yang dapat merusak jati diri pemuda. Kegiatan ini bertujuan sebagai media silaturrahim pemuda sekelurahan Bedahan, sebagai proses belajar pemuda menuju pemuda harapan masyarakat, menyiapkan generasi yang qurani yang siap terjun mengayomi masyarakat, membekali pemuda agar mampu mengelola organisasi masjid dan sumber-sumber keuangan masjid dengan baik dan benar. Target kegiatan ini adalah para remaja dan pemuda yang berasal dari 8 masjid yang ada dan remaja/pemuda dari 9 rukun warga/ lingkungan/ yang ada di kelurahan
Bedahan, sebagaimana dapat dilihat pada tabel 2.1.

Tabel 2.1 Asal Peserta Pelatihan

\begin{tabular}{cl}
\hline No & \multicolumn{1}{c}{ Organisasi/Lembaga } \\
\hline 1 & $\begin{array}{l}\text { Badan Komunikasi Pemuda Masjid } \\
\text { (BKPM ) }\end{array}$ \\
\hline 2 & Ikatan Remaja ( IRMA) Arriyad \\
\hline 3 & $\begin{array}{l}\text { Aktiviatas Remaja Islam ( ARISMA) } \\
\text { Al-Mukhlisin }\end{array}$ \\
\hline 4 & $\begin{array}{l}\text { Kesatuan Remaja Islam Masid Al- } \\
\text { Hidayah ( KARISMA) }\end{array}$ \\
\hline 5 & $\begin{array}{l}\text { Ikatan Remaja Syamsul Iman } \\
\text { ( IRMASI ) }\end{array}$ \\
\hline 6 & $\begin{array}{l}\text { Forum Remaja Masjid Qurota A'yun } \\
\text { (Formas-Q ) }\end{array}$ \\
\hline 7 & $\begin{array}{l}\text { Ikatan Remaja Islam Masjid Al- } \\
\text { Hikmah ( IKRIMA ) }\end{array}$ \\
\hline 8 & $\begin{array}{l}\text { Aktivitas Remaja Masjid } \\
\text { Baiturrahman ( ARISBA ) }\end{array}$ \\
\hline 9 & $\begin{array}{l}\text { Aktivitas Remaja Masjid Al-Hidayah } \\
\text { ( ARISMA ) }\end{array}$ \\
\hline 10 & Lingkungan RW 01 \\
\hline 11 & Lingkungan RW 02 \\
\hline 12 & Lingkungan RW 03 \\
\hline 13 & Lingkungan RW 04 \\
\hline 15 & $\begin{array}{l}\text { Lingkungan RW 05 } \\
\text { (In) }\end{array}$ \\
\hline
\end{tabular}

15 Lingkungan RW 06

16 Lingkungan RW 07

17 Lingkungan RW 08

18 Lingkungan RW 09

Hasil atau luaran yang diharapkan dari kegiatan ini adalah terjalinnya silaturahmi antar pemuda sekelurahan Bedahan, dan pemuda Bedahan mampu menjadi figur panutan di masyarakat. Setelah pelatihan peserta diharapkan : 
1. Peserta mendapatkan tambahan pengetahuan mengenai kepemudaan, pembangunan, organisasi, kepemimpinan dan kewirausahaan

2. Terbentuknya kader-kader pemuda yang akan mengelola/memimpin masjid di masa yang akan dating

3. Terbentuknya kader-kader pemuda sebagai agent pembangunan di kelurahan Bedahan

4. Terbentuknya pemuda-pemuda yang mempunyai karakter yang baik yang tidak mudah tergoda oleh budayabudaya yang dapat merusak jati diri pemuda.

Bagi tim abdimas Unindra PGRI kegiatan ini diharapkan juga dapat menjadi sarana mengimplementasikan ilmu dan kemampuan yang dimiliki kepada pada masyarakat serta menghasilkan artikel ilmiah mengenai pengabdian masyarakat yang dapat dimuat pada jurnal ber ISSN.

\section{METODE PELAKSANAAN}

Berdasarkan analisis situasi dan permasalahan yang dihadapi mitra maka langkah-langkah yang dilakukan untuk mencapai target, sasaran, tujuan dan hasil yang diinginkan maka diadakan pendekatan terhadap salah satu organisasi kepemudaan yang ada di kelurahan Bedahan, yaitu BKPM. Pendekatan yang dilakakukan dengan mengadakan komunikasi dengan ketua umum BKPM. Kegiatan ini tidak hanya memberikan Latihan Dasar Kepemimpinan, tetapi juga pelatihan kewirausahaan, peran pemuda dalam pembangunan. .

Partisipasi mitra dalam hal ini adalah BKPM kelurahan Bedahan diperlukan agar pelaksanaan kegiatan ini dapat berjalan dengan baik. Partisipasi mitra antara lain :

1. Mengundang organisasi ikatan remaja masjid agar mengirimkan utusan/perwakilan untuk mengikuti kegiatan ini.

2. Menyediakan sarana dan prasarana untuk kegiatan ini seperti tempat, meja dan kursi dan peralatan sound sistem.

3. Membantu mencari dana yang dibutuhkan.

Sedangkan tim abdimas menyiapkan makalah, menggandakan sebanyak yang diperlukan dan menyampaikannya kepada peserta serta melakukan dialog interaktif dengan peserta.

\section{HASIL DAN PEMBAHASAN}

Agak sulit untuk mengetahui dan melihat apakah kegiatan pengabdian kepada masyarakat yang dilaksanakan telah memberikan hasil dan luaran yang diinginkan. Mengapa demikian? karena kegiatan pengabdian kepada masyarakat yang dilakukan bukan memberikan suatu pendidikan ketrampilan, tetapi lebih kepada pendidikan pembentukan karakter pemuda untuk menghadapi tantangan zaman. Hasil yang dicapai sebagai berikut :

1. Peserta mendapatkan tambahan pengetahuan mengenai kepemudaan, pembangunan, organisasi, kepemimpinan dan kewirausahaan

2. Terbentuknya kader-kader pemuda yang akan mengelola/memimpin masjid di masa yang akan dating

3. Terbentuknya kader-kader pemuda sebagai agent pembangunan di Kelurahan Bedahan

4. Terbentuknya pemuda-pemuda yang mempunyai karakter yang baik yang tidak mudah tergoda oleh budayabudaya yang dapat merusak jati diri pemuda.

\section{SIMPULAN}

Berdasarkan analisis situasi dan kegiatan yang telah dilaksanakan dapat 
disimpulkan bahwa Kelurahan Bedahan memiliki potensi sosial ekonomi yang masih dapat dikembangkan. Sumberdaya alam yang belum tergarap dengan baik, misalnya ketersediaan lahan untuk perumahan, pertanian, perkebunan dan lain sebagainya. Sumberdaya manusia yang melimpah yang harus dapat disiapkan untuk menjadi kader-kader pembangunan, pelaksana pembangunan, agent-agent perubahan dimasa yang akan datang. Sumberdaya manusia yang masih melekat dan memegang serta menjalankan norma-norma keagamaan. Sumberdaya manusia yang masih dapat berkembang dengan pembinaan-pembinaan yang kontinu baik dari pemerintah, lembaga-lembaga pendidikan berupa kuliah kerja nyata, pengabdian kepada masyarakat.

BKPM agar lebih mengintensipkan komunikasi dengan lembaga-lembaga pendidikan tidak hanya kepada Unindra PGRI tetapi juga Perguruan Tinggi lainnya agar programprogram kerja BKPM dapat terbantu pelaksanaannya dengan tersedianya tenaga akhli dari Perguruan Tinggi sebagai narasumber. Bagi tim abdimas dan dosen-dosen lainnya dari Unindra PGRI dapat menjadikan Kelurahan Bedahan sebagai lahan atau lokasi kegiatan abdimas lainnya dengan bekerja sama yang saling menguntungkan dengan BKPM dan lembaga swadaya lainnya yang ada di Kelurahan Bedahan

\section{DAFTAR PUSTAKA}

Hurlock, E.B., (1991). Developmental Psychologi A. Life-Span Approach, terjemahan : Psikologi Perkembangan Suatu Pendekatan Sepanjang Rentang Kehidupan. Jakarta: Penerbit Erlangga.

Robbins. (2010). Perilaku Organisasi. Jakarta: Salemba Empat.

Sarwono, S.W. (2010) Psikologi Remaja, Jakarta: Rajawali Press,

Yuki, G. (2010). Leadership In Organization. New Jersey: Prentice Hall. 